\title{
The Study of Understatement as Adaptation to the Mental World of the Communicators
}

\author{
Liyao Miao ${ }^{1, a}$, Ying Zhan ${ }^{2, \text { b, * }}$ \\ ${ }^{1}$ Foreign Language Teaching and Research Section of the Rocket Force University of Engineering, \\ Xi'an, P.R. China \\ ${ }^{2}$ Foreign Language Teaching and Research Section of the Rocket Force University of Engineering, \\ Xi'an, P.R. China \\ a18629140094@163.com bzhanyingsarah@163.com \\ ${ }^{*}$ Corresponding author
}

Keywords: Adaptation Theory, Mental world, Understatement, Communication.

\begin{abstract}
This thesis draws support from Verschueren's Adaptation Theory to analyze how speakers adapt to the mental worlds of the participants in the communication, including the adaptation to participants' emotional involvement, personality traits, motivations and desires. Through this study people may realize the importance of understatement as a pragmatic strategy for a successful communication and the necessity for the cultivation of understating ability.
\end{abstract}

\section{Introduction}

Understatement is a frequently used pragmatic strategy in daily communication. It employs the mild and restrained words to replace the direct and unpleasant words in order to a0ttenuate the tone of utterance, ease the communicational atmosphere, cover people's embarrassment, evoke more positive feelings, maximize the emotional acceptability of the propositional content, increase the sense of humor and to show the politeness of the speaker. It is a quite efficient linguistic strategy.

Scholars home and abroad have conducted fruitful researches on understatement from the perspective of rhetoric, semantics, sociology, psychology and pragmatics. But most of the researches only focus on the interpretation of understatement rather than its production mechanism; some pay much attention to the linguistic forms of understatement but ignore the factors (culture, society, psychology...) influencing and leading to the production of this unique linguistic phenomenon.

This paper attempts to apply some viewpoints in Verschueren's Adaptation Theory to analyze understatement. In his theory, Verschueren believes that mental world plays an important role in verbal communication. He also notes that verbal interaction is communication from mind to mind. The mental world then, refers to both the utterer and the interpreter's mental world, which means that when making linguistic choices, besides considering his own mental conditions like the communicative aims or emotions, the utterer should adapt to a series of mental factors of the interpreter like the personality and motivation as well.[1]

Moreover, Verschueren holds that the mental world consists of cognitive and emotive elements. The former are the conceptualization of the social reality in terms of which social interactions is interpreted while the latter focuses on the attitudinal prerequisites for engaging in, sustaining and coloring interaction.[ibid] This thesis will keep its attention to the emotive elements including people's personality, emotions, motivations/intentions, beliefs, desires, and so on. To put it specifically, how people understate to adapt to their own or the listener's personality, emotions, motivations and desires in order to make a successful communication and maintain a harmonious relationship will be this paper's focus. 


\section{Understatement as Adaptation to the Mental World}

\subsection{Adaptation to the Emotion}

People experience joy, anger, sadness and love everyday. These emotions may accordingly shape and trigger different linguistic choices. What the utterer says about the same thing in a good mood may be different from what he says in a bad one. Similarly, if the interpreter is in a good mood, he may not mind too much what the utterer says and will not get upset or angry easily. Otherwise, he might be offended by those same words. In this sense, during the process of communication, it is necessary for the utterer to pay attention to his own present state of mind and make appropriate linguistic choices in order to realize certain communicational aim. At the same time, the utterer must be careful of the interpreter's emotional condition and choose right expressing ways so as to ensure the smoothness and success of the communication and the maintenance of their relationship. Understatement distinguishes itself by its mild, reserved, roundabout, and tactful ways of expression.[2] Those polite and refined words or phrases can hardly hurt the feelings or emotions of the communicators. The following examples can clearly illustrate this viewpoint.

(1) The anxious parents are waiting for the diagnostic result of their sick son. Then the diagnostician came out from the office.

Father: How about my son?

Doctor: That's not so bad. He might recover gradually after the surgery.

(Source: "Prison Break", the 2nd Season, Episode7)

Apparently, the doctor covers the real condition of his little patient. He uses "not...bad" and "might" to understate the condition of his patient for comforting the anxious parents. This reserved understatement adapts to the emotional condition of these parents, pacifies the worried couple, and raises their hopes for the quick recovery of their son. Meanwhile, the answer of the doctor adapts to his own emotion, sympathizing with and showing respect to the parents.

(2) Mr Wang and Mr Zhang are good old friends. They haven't met each other for several years. (Mr Wang's son is a famous professor in a University. Mr Zhang's son works in a local factory which might close soonly.)

Mr Wang: What does your son do?

Mr Zhang: Oh, he is a plumber. You know that, sometimes he is busy, but sometimes he has no business at all. Then, how about your son, so many years, I even can't remember his looks......

Mr Wang: Oh, he is something of a teacher.

(Source: Daily conversation)

Wang does not want to show off his successful son in front of Zhang. He describes his son's profession reservedly and modestly, and understates the quality of his son's work, which keeps Zhang from the embarrassment. For Chinese parents, the success of the child will be their biggest pride and their own success. Mr Wang is aware of Mr Zhang's emotion, and makes a good adaptation to that, which saves Zhang's face to some extent.

(3) Little Tom is a mischievous imp at school. One day, Tom's mother was invited to school by the teacher.

Tom's mother: So, is there anything wrong with Tom?

Teacher: Yes, a little problem. Tom is undoubtedly a difficult pupil for he has a strongly independent mind, and is impatient of accepting rules of classroom. And I think he needs to take his lessons more seriously and develop quieter habits of communication.

(Source: “Desperate Housewives”, the 2nd Season, Episode 12)

The teacher knows clearly that no parents would accept any negative remarks on their kids easily. Her statement is an understatement of Tom's poor performance at school. This experienced teacher tactfully and indirectly describes Tom's performance, which attenuates the degree of the negative comment on Tom, adapts to the mother's emotional condition, saves the mother's face, and maintains a harmonious communicational atmosphere.

\subsection{Adaptation to the Personality}

Another mental ingredient of communicators is the personality. The personality of the utterer to a 
large extent determines the linguistic choices he makes. For instance, an optimistic utterer and a pessimistic utterer may express their feelings in different ways; a humorous utterer and a dull utterer may create totally different communicative atmosphere. As a language strategy, understatement can reflect the personality of the utterer in a way. The following examples may make this clear:

(4) Linda is taking part in a job interview, before that she worked in a small vocational hotel as a part-time worker. During the interview, there are lots of questions about Linda's work experience.

Interviewer: Linda, you said that you have been working in a small vocational hotel, so what is your feeling when the boss of the hotel orders you to do many trifles that you dislike to do?

Linda: Well, even though I wanted to say, "Go get it yourself”, I knew it was my job to be quiet and do in a nice way whatever I was told.

(Source: "Fashion")

It can be inferred that "to be quiet" is the understatement of "to be tolerant". Linda's words reflect her strong will and persevering personality, which just adapt to the requirement for a competent worker. The tactful wording which adapts to Linda's personality ensures her a successful interview and forebodes a beautiful future for her.

(5) Hortensia Cabrera, mother of 14, widow...leads an extremely hard life. But her description on the living condition is out of everyone's expectation. "Money", she says with quite understatement, "is kind of tight. But I manage".

(Source: National Geographic Channel)

The mother consciously understates her poverty-stricken condition, and describes that as "kind of tight”. Obviously, this mother is full of courage to face the hard future life. She does not need the sympathy and mercy from the outside, and refuses to come to terms with her fate, but hangs on to life bravely. The mother's understatement to her economic condition adapts to her personality traits.

Besides making adaptation to utterer's own personality in communication, the interpreter's personality should also be taken into consideration. Verschueren suggests that the utterer makes adaptation to the personality of the interpreter by choosing the proper linguistic forms.[3]

(6) Being husband of Anna, Aaron knows well about her introverted wife who is easily to be hurt and always feels frustrated once her effort is negated by others. One day, Anna cooked some beef carefully for dinner. The following is the exchange between the couple:

Anna: Honey, how do you think about this beef, do you like it?

Aaron: Hmm, it's nice. And a little more time might make it better.

Anna: Really? Well, next time I will keep them in the pan for a longer time.

(Source: Daily conversation of the author's American friends)

"A little more time might..." maximizes the emotional acceptability of the propositional content. Aaron's wording adapts to Anna's personality well, ensuring a harmonious relationship, which may be one of the tips for the happy marriage of this couple.

\subsection{Adaptation to the Motivation/Intention}

Psychological motivation/intention is the motive for the initiation and development of a communication. Usually, an utterer will seldom miss the chance of making adaptation to his own motivation/intention in communication. To create a harmonious communicational atmosphere and keep the communication going smoothly, the interpreter's motivation/intention will be taken into utterer's consideration as well.

\subsubsection{Criticism}

To maintain the relationship with the interpreter, and to make the interpreter accept the criticism agreeably without hurting his face, the utterer usually understates the seriousness or poor condition of the problem, which will keep the communication from breakdown.

(7) TV reporter: Would you mind telling me frankly what you think of our programs?

One of the audiences: Well, some are interesting, some could be better, and some are sort of rubbish.

(Source: Ju Hong, 2006) 
The wordings of this audience could be regarded as kind of criticism, but this mild and roundabout remark is easier to be accepted than a direct one.

\subsubsection{Humor-creating}

In some situations of daily communication people understate, but they don't mean it. At this time, understatement is just for fun or for creating a happy and relaxing communicational atmosphere.

(8) It is the lunch time, several clerks gather together while enjoying their food.

Mindy: Oh, God, I can not eat any more. It is too much for me.

Caleb: Come on, Mindy. Are you kidding? You know what, I usually have five sandwiches and a quart of milk for my snack.

(Every one laughs......)

(Source: Daily conversation in an office)

Obviously, Caleb makes an understatement because he wants his companies to be happy and relaxed after the hard work. Caleb's humorous language causes everyone to laugh and makes them forget the tiresome and vexation.

\subsubsection{Commitment—avoiding}

People are very cautious of their words and deeds on many matters in order to escape from taking responsibilities. Understatement is a language device for attenuating the tone of utterance. It is a good language strategy to notify that the utterer is not completely certain of a reported state of an affair or of his position in certain matter.

(9) In the editorial department, the editor is asking something about Jame's work.

Editor: Could you give me some information about how long it will take to finish your task?

Jame: Well, the quote might be done within three or four days but the job won't be done for at least five weeks.

(Source: Daily conversation in an editorial department)

Jame is not sure how long it will take to finish his job, so he employs the fuzzy numbers consciously to leave him a flexible deadline. In this case, he will not be blamed by his superior if he fails to finish the task before the deadline. So James smartly adapts to his own motivation of avoiding commitment.

\subsubsection{Encouragement}

Since the illocutionary force of understatement is not strong enough to express how bad or serious something really is, people prefer to choose understatement as a way of comforting or showing support to their communicational partner who may has experienced a loss, failure or difficulty.

(10) Melanie has taken part in several job interviews but she hasn't received any offer since the beginning of her job-hunting. Melanie is very depressed and unloads her worries and pressure to her friend Candy.

Melanie: I'm worried about myself now. I think I'm not good enough to take any position.

Candy: Oh, no. It is not the case. Nearly no one can find a job effortlessly. You are not at all unwelcome by those companies. They need time to pick up a few qualified from hundreds of interviewees. What you need is a little more patience, which is one of the most valuable qualities of a competent employee.

Melanie: Do you think I will have the chance?

Candy: I do think so.

(Source: "College Road Trip")

The double negative "no...effortlessly" and "not at all unwelcome" express the hardship of job-hunting and Melanie's chance of getting the job. Candy's understatement passes on comforting and supporting affection to Melanie and evokes deeper encouragement to her friend of not being defeated by frustration and temporary failure.

\subsubsection{Solidarity-building}

Few people would like to be excluded from his group because of his dissimilarities from the other group members.

(11) Tom and Cyril hold similar ideas for the further developing plan of the company, so they tacitly approve each other as each one’s best working partner. 
Cyril: I believe that the investment to the West Coast market will bring our company unbelievable interests.

Tom: I couldn't agree any more.

(Source: “Desperate Housewives", the $3^{\text {rd }}$ Season, Episode 4)

The negative structure "not...more" is a form of understatement, it has strong illocutionary force though being transmitted through a negative tone. Tom employs this understatement to indicate his consent and support to Cyril's idea in a roundabout but effective way, helping consolidate the relationship between them. Besides, understatement can also help people maintain their in-group identity, which at the same time ensures the solidarity of a group.

(12) Edie is asked to take care of her little brother at home because her mother goes to the supermarket. Then, she hears that someone is knocking at the door...... (They are Edie's friends.)

One of Edie's friends: Hi, Edie. We are going to sell cookies baked by ourselves at the local market to raise money for the charity. We are wondering whether you would like to go with us.

Edie: I would certainly go if I had the time.

(Source: “The Cheetah Girls”, Episode 1)

The subjunctive mood applied here aims at expressing the emotion of helplessness. Edie tactfully expresses her feeling with a sense of regret, which implies the meaning of refusal, but helps Edie avoid her friends' misunderstanding and keeps her an in-group identity.

\subsection{Adaptation to the Desire/Wish}

People always do their best to realize their wishes. Sometimes, the words or expressions may reveal communicators' desires. Usually, to achieve an effective and smooth communication and keep a harmonious relationship, both the utterer and the interpreter should take each other's desire into consideration.

(13) There is a family discussion about which tourist attraction will be the family's visiting destination during summer holiday. It seems that there are some contradictions between the mother and the daughter (Rebecca).

Mother: Egypt is where I have yearned for traveling for many years. It is really mysterious. I do want to feel the Pyramids personally.

Daughter: It is too hot to go there in summer. We should find out a cool place where we can swim and go surfing. It is really cool and excited.

(Looking forward to getting support from her father, Rebecca looks at him hopefully.)

Father: It is a little bit hot this summer. A cool place is more or less reasonable.

Mother: OK, you guys win!

(Source: Daily conversation)

The father employs a mild and roundabout expression to support his daughter's suggestion to avoid displeasing his wife. The fuzzy expressions "a little bit" and "more or less" mitigate the degree of his opposition to his wife's proposition, and adapt to his daughter's desire without hurting the mother's feeling.

\section{Summary}

A good speaker can apply all kinds of linguistic strategies skillfully for realizing his communicational purpose. This communication competence is not a born ability but one which is practiced and cultivated in innumerable real communications and is under the guidance of a high level of intentions. As an efficient linguistic strategy, understatement is preferred by lots of language users, but that doesn't mean every one can use understatement appropriately at any time, any place or to any person. Problems caused by the misuses of understatement happen every day. For example, some people regard understatement as a blind self-depreciation. Understating behaviors under the guidance of this false understanding makes the listener believe that the speaker is hypocritical and untruthful, therefore there comes out a communication and friendship breakdown. In this sense, the cultivation of understating ability is necessary and urgent. In the process of communication, every one should show a great consideration of the thoughts and 
feelings of others by putting oneself in somebody else's position, i.e. empathize with their communicational partners. Based on this mutual understanding and respect, language users choose appropriate understating forms in terms of various contextual correlates to help them realize the communicational aims.

In addition, the linguistic devices used to understate should be accumulated in daily communicational practices. People need to take careful account of those expressing forms and be sensitive while applying them. Day by day, every one will form their own language ideology of understatement, through which the metapragmatic awareness will be aroused. Under the guidance of this high level of salience, people will communicate smoothly and become competent language users.

\section{References}

[1] Verschueren, J., Understanding Pragmatics. Foreign Language Teaching and Research Press. Edward Arnold Publisher Ltd, Beijing, pp. 55-57,1999.

[2] Hübler, A., Understatement and Hedges in English. Amsterdam and Philadelphia, PA: John Benjamins Publishing Company, pp. 168-169,1983.

[3] Hong Ju, Manchun Dai, A Study of Understatement as a Pragmatic Strategy from an Adaptation-Based Perspective, Foreign Language Teaching and Research Section, vol.38, pp. 11, 2006. 